\title{
An Unusual Case of Headache Presenting to Emergency Department: Late Onset Ventriculo-Peritoneal Shunt Fracture
}

\author{
Huma Haseeb ${ }^{1 *}$, Guirish A Solanki ${ }^{2}$, Munir Haque ${ }^{1}$, and Stephen Ting ${ }^{1}$ \\ ${ }^{1}$ Departments of Acute Medicine, Good Hope Hospital, Heart of England NHS Foundation Trust, University of Warwick, UK \\ ${ }^{2}$ Department of Paediatric Neurosurgery, Birmingham Children Hospital, Birmingham, United Kingdom
}

*Corresponding author: Huma Haseeb, Clinical Fellow, Department of Acute Medicine, Good Hope Hospital, Heart of England NHS Foundation Trust, Rectory Road, Sutton Coldfield B75 7RR, Birmingham, UK, Tel: +44 121424 2000; E-mail: huma.haseeb@heartofengland.nhs.uk

Rec Date: October 16, 2017, Acc Date: October 24, 2017, Pub Date: October 26, 2017

Citation: Haseeb H, Solanki GA, Haque M, Ting S (2017) An Unusual Case of Headache Presenting to Emergency Department: Late Onset Ventriculo-Peritoneal Shunt Fracture. Med Case Rep Vol.4 No.1:49.

\section{Abstract}

\begin{abstract}
A 17-year-old male with a ventriculo-peritoneal (VP) shunt inserted at 8 months of age presented to the Emergency Department (ED) with headaches. He had attended the ED a week earlier with headaches but because a CT head scan at the time was reportedly normal, he had been discharged with instruction to re-attend in case of deterioration. A repeat CT head scan again demonstrated no evidence of acute hydrocephalus or a blocked VP shunt. However, a shunt series revealed a short shunt catheter interruption and a kink at the neck region. The patient was transferred to a tertiary paediatric neurosurgical unit on the same day and underwent an uneventful surgery.
\end{abstract}

Keywords: Elephantiasis; Lymphedema; Intensive treatment; Diagnosis; Lymph drainage

\section{Introduction}

Physicians in emergency department (ED) encounter a variety of adult patients with acute headaches. The main objective of assessment is to identify those with potentially fatal or disabling intracranial conditions. The strategy to achieve this may appear deceptively simple albeit through careful history taking, clinical examination and radiological imaging. Our patient had a complex past history who presented with a common symptom of headache but harboring a rare etiology that was only identified on a latter hospital re-admission. This case highlighted the importance of taking patient's complains and readmission seriously, paying particular attention to prior related background history, the need to keep an open mind to the possibility of other diagnosis in patient with persisting headache and carry out prompt investigation using a different modality whilst liaising with specialist at tertiary centre. Importantly, this case study demonstrates that pediatric-inserted ventriculo-peritoneal (VP) shunt and its mechanical malfunction occurring in adulthood though rare, may present sub-acutely to ED.
Furthermore, this serves as a lesson that VP shunt-series must be considered in patients with VP shunt presenting with persistent or progressive headaches despite normal head CT.

\section{Case Presentation}

A 17-year-old young male presented to the ED in a nonneurosurgical hospital with a 3 days history of headaches, nausea and vomiting. He had a past history of aqueductal stenosis and underwent a VP shunt insertion at 8 months old. He had remained well and his last Paediatric Neurosurgery clinic review 10 months previously was unremarkable with an adult follow-up transition request placed. Urgent CT scan of head was requested which revealed a VP shunt proximal catheter in the right lateral ventricle with no evidence of hydrocephalus and intra or extra-axial bleeding. He was advised of a likely self-limiting viral illness and discharged home the same day.

Seven days later, he was re-admitted with increased severity of headache and nausea. Collaborative history from his parents described features of irritability, constant nasal rubbing and increased lethargy during the 3 days prior to readmission. On examination, the patient was alert with a GCS of 15 out of 15, afebrile and blood pressure was 110/76 $\mathrm{mmHg}$. Neurological examination of cranial nerves and limbs did not revealed abnormality.

Blood tests included serum sodium of $134 \mathrm{mmol} / \mathrm{L}$ (reference range 133-146 $\mathrm{mmol} / \mathrm{L})$, urea $4.6 \mathrm{mmol} / \mathrm{L}$ (2.5-7.8 $\mathrm{mmol} / \mathrm{L})$, creatinine $68 \mu \mathrm{mol} / \mathrm{L}(64-111 \mu \mathrm{mol} / \mathrm{L}), \quad$ C-reactive protein less than $1 \mathrm{mg} / \mathrm{L}(0-5 \mathrm{mg} / \mathrm{L})$, mildly raised white cell count $12.8 \times 10^{9} / \mathrm{L}\left(4.0-11.0 \times 10^{9} / \mathrm{L}\right)$ and neutrophilia $9.3 \times$ $10^{9} / \mathrm{L}\left(2.0-7.5 \times 10^{9} / \mathrm{L}\right)$. A repeat CT head again did not show evidence of acute obstructive hydrocephalus or a blocked VP shunt and it was reportedly unchanged to the scan done at his first presentation. At this point, the possibility of mechanical VP shunt complication was also considered.

A VP shunt-series were subsequently performed. The proximal tip of the VP shunt and its port were seen on the lateral view of the skull x-ray (Figure 1). 


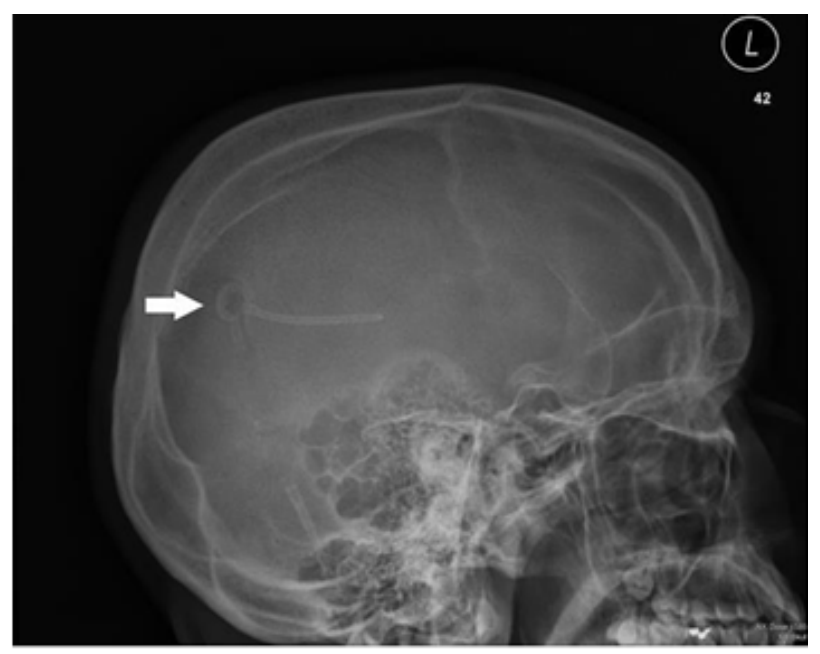

Figure 1 The proximal tip of the VP shunt and its port were seen on the lateral view of the skull $x$-ray.

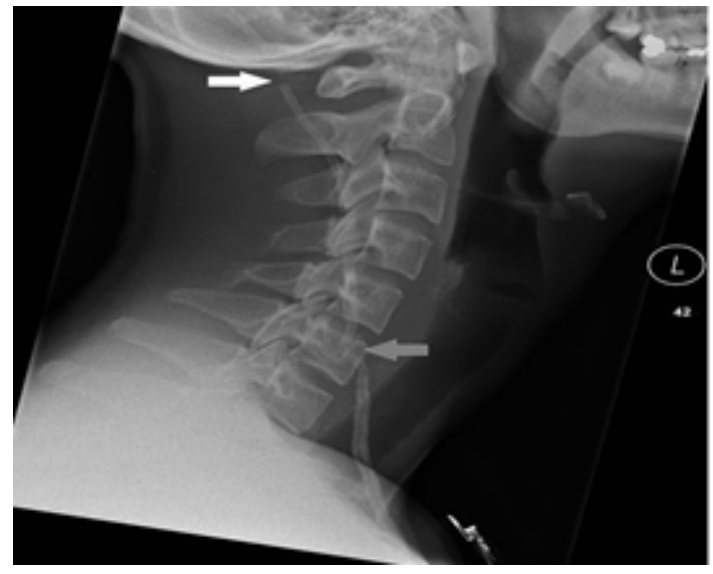

Figure 2 As the catheter travelled down the neck, a short 6 $\mathrm{mm}$ interruption at the level of $\mathrm{C} 1$ representing a shunt fracture was noted (white arrow).

As the catheter travelled down the neck, a short $6 \mathrm{~mm}$ interruption at the level of $\mathrm{C} 1$ representing a shunt fracture was noted (white arrow, Figure 2). Further down at the level of C6, the catheter appeared kinked despite a normal alignment of C-spine from C1 to C7 (Grey arrow, Figure 2). The shunt catheter was well delineated on the right side of the thorax (Figure 3) with the exit tip seen at the lower abdominal area as it entered the peritoneal cavity (Figure 4).

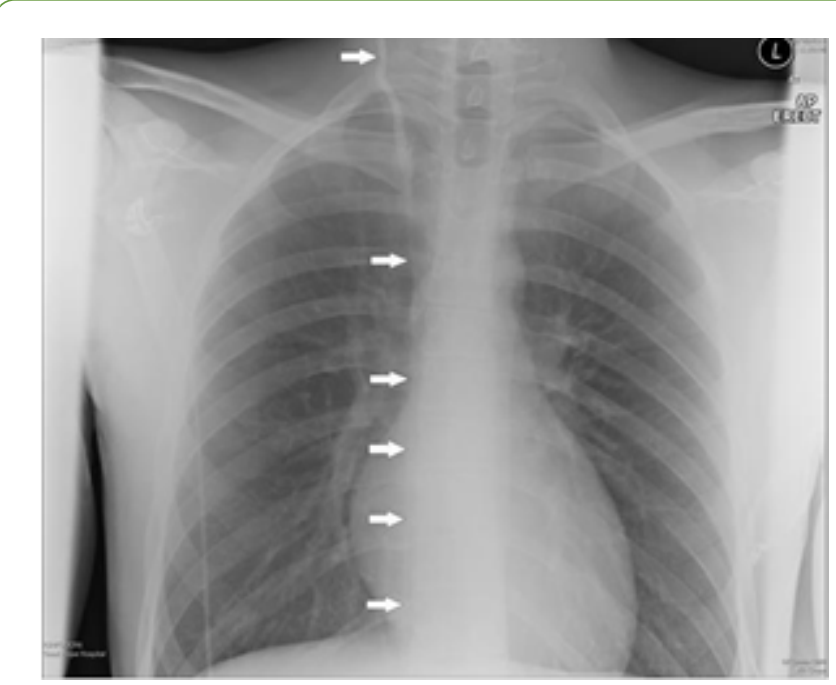

Figure $\mathbf{3}$ The shunt catheter was well delineated on the right side of the thorax.

A single dose of intravenous acyclovir and ceftriaxone administered on admission was discontinued following the radiological findings of fractured VP shunt. The patient was transferred to a tertiary pediatric neurosurgical unit on the same day and underwent surgery. Intraoperatively, the proximal section of the VP shunt was found to be functional. Retrieval of the whole catheter was attempted but the catheter was tethered distal to the fracture site in the upper chest and at the abdominal incision site. As a result, a new distal catheter was inserted. The patient had a complete recovery and was discharged home two days later.

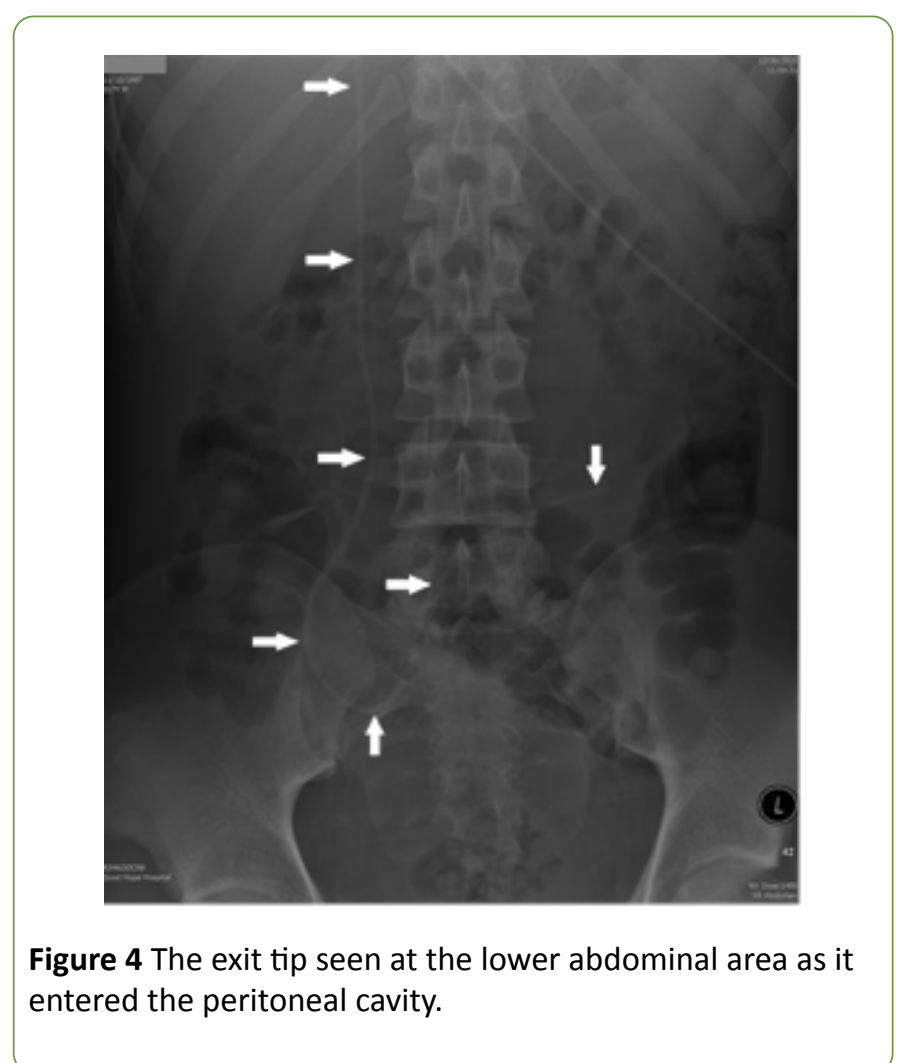




\section{Discussion}

The prevalence of pediatric VP shunt malfunction that encompasses infection, obstruction or fracture is reported to be as high $39 \%$ at 1 year and $53 \%$ at 2 years after shunt insertion [1]. Our case study demonstrates a late onset of VP shunt fracture with a normal CT scan and no evidence of hydrocephalus, occurring 16 years following initial placement. Among the recognized complications of VP shunt, disconnection or fracture of the shunt is the second most common cause of shunt failure after infection [2]. Shunt fracture can occur at any site of connection along the course of tubing, but the most common site of breakage is in the neck, followed by the scalp at either the proximal or distal valve or connecting devices [3]. Radiographic review of a consecutive shunt-series reported the commonest abnormalities were fractures/tears (53\%), followed by disconnection (31\%) and combined accounting for over $84 \%$ of abnormalities [4]. Approximately one-third of the abnormalities occurred above the valve while two-thirds were below the valve level. The majority of these were seen in the neck (48\%), followed by the abdomen (28\%) and the chest (24\%) [4]. Proximal VP shunt malfunction commonly occurs in the first 2 years of shunt placement while distal shunt malfunction is generally seen 2 years following surgery [5]. The interval from shunt insertion to shunt-series abnormality has been reported to be greater than 2 years in $85 \%$ of cases [4]. Overall proximal shunt malfunction of any cause far surpasses distal malfunctions/ fracture. In an institutional series of 120 patients that underwent 132 shunt-series, no fractures, disconnections or migrations were noted less than 2 years from implantation [4]. Calcification of the outer silicon rubber wall of the shunt with time causes fixation of the catheter to the surrounding fibrotic subcutaneous tissue. The resulting reduction in motion of the shunt components generally serves to maintain its integrity. However, the continuous motion of the neck leads to stretching of the tube between 2 points of fixation thereby predisposing it to fracture at the cervical region as seen in our patient. Excessive strain between 2 points along the shunt tube is highest during the maximal spinal growth rate seen from newborn to 5 years old with the second peak of growth albeit at a slower rate at 10 years old [6]. This explains the high risk of shunt fracture within the first 10 years of life [3]. However, the rare occurrence of shunt fracture in our patient could well be due to 16 years of spinal lengthening causing further strain to the tissue-fixated tube.

Neurosurgical assessment of patients with VP shunt, aged 2year and older may include CT or MRI head every 2 years $[7,8]$. However, shunt-series have been used variably in the evaluation of shunt malfunctions particularly in the paediatric population [4]. In some centers they are used routinely while other centers are selective. In order to minimize the potential risks of biological effects associated with radiation, dose limits and guidelines have been established. Regardless, there is a need to strive to keep radiation exposure well below these, through the principle of ALARA, "as low as reasonably achievable" radiation exposure [4]. Patients with shunt fracture can also present with signs of raised intracranial pressure and a palpable gap or fluid collection in the shunt track. However, these features may not be evident in subacute presentation along with normal ventricular dimensions on head CT [9]. This was clearly the case in our patient, which highlights the importance of considering shunt-series to determine patency or continuity of VP shunt catheter despite normal brain CT and absence of clinical features of mechanical malfunction. About $18 \%$ of abnormalities are detected by shunt-series, suggesting a complementary and useful role in selected cases. Determining clinical indications and improving criteria for performing a radiographic study will optimize yield while minimizing radiation exposure [4].

\section{Conclusion}

\section{Why should an emergency physician be aware of this?}

Pediatric-inserted VP shunt and its mechanical malfunction occurring in adulthood are rare but may present sub-acutely to non-neurosurgical district hospital. In cases where shunts have been inserted in childhood, with an interval of shunt insertion to presentation greater than 2 years, consider catheter fracture or disconnection in the differential diagnosis and perform a shunt series. VP shunt-series must be considered in patients with VP shunt presenting with persistent or progressive headaches but normal head CT.

\section{References}

1. Drake JM, Kestle JR, Milner R, Cinalli G, Boop F, et al. (1998) Randomized trial of cerebrospinal fluid shunt valve design in pediatric hydrocephalus. Neurosurgery 43:294-303.

2. Kang JK, Lee IW (1999) Long-term follow-up of shunting therapy. Child's Nervous System: CHNS: Official Journal of the International Society for Pediatric Neurosurgery. 1999 15: 711-717.

3. Aldrich EF, Harmann P (1990) Disconnection as a cause of ventriculoperitoneal shunt malfunction in multicomponent shunt systems. Pediatric neurosurgery 16: 309-311.

4. Almond M, Joseph R, Chapman S, Kay A, Walsh AR, et al. (2007) $A$ review of radiographic shunt-series in the detection of paediatric shunt malfunctions. Child's nervous system: ChNS: official journal of the International Society for Pediatric Neurosurgery 23: 1047-1090.

5. Kast J, Duong D, Nowzari F, Chadduck WM, Schiff SJ (1994) Timerelated patterns of ventricular shunt failure. Child's Nervous System: CHNS : Official Journal of the International Society for Pediatric Neurosurgery 10: 524-528.

6. Chiriac A PI, Iliescu B (2012) Mechanical failures of ventricularperitoneal shunts. Romanian Neurosurgery XIX: 226-269.

7. Lehnert BE, Rahbar H, Relyea-Chew A, Lewis DH, Richardson ML, et al. (2011) Detection of ventricular shunt malfunction in the ED: relative utility of radiography, CT, and nuclear imaging. Emerg Radiol 18: 299-305.

8. http://emedicine.medscape.com/article/1135286-overview 
9. http://learningradiology.com/notes/generalnotes/ shuntfxcorrect.htm 